\title{
The Co-production of Biomedical Research in Canada: Are Scientists Ready to Take the Plunge? An Empirical Example from Food Allergy Research
}

\author{
Jenna Dixon ${ }^{1, *}$, Susan J. Elliott ${ }^{1}$, Ann. E. Clarke ${ }^{2}$ \\ ${ }^{1}$ Department of Geography and Environmental Management, University of Waterloo, Canada \\ ${ }^{2}$ Department of Medicine, University of Calgary, Canada
}

Copyright $\subset 2017$ by authors, all rights reserved. Authors agree that this article remains permanently open access under the terms of the Creative Commons Attribution License 4.0 International License

\begin{abstract}
End-user involvement in research through collaborative research models, known as Integrated Knowledge Translation (IKT) in Canadian health, can improve recruitment, quality, relevance and acceptability of research. Despite potential benefits, application to biomedical research remains rare. This study aims to explore baseline knowledge, attitude and practices of Canadian biomedical scientists towards IKT as a foundation for a funded program of research related to causes and treatments of an emerging public health epidemic. A qualitative methodology was used. Semi-structured in-depth interviews were conducted with all 16 scientists on the GET-FACTS project. Interviews were audio-recorded and transcribed verbatim. Thematic content analysis was performed on the data. Findings highlight the limited exposure of biomedical scientists to IKT activities. Though Knowledge Translation (KT) was a term familiar to participants, most described it as end of grant activity (not 'integrated'). A majority of participants expressed that their research could take on a new direction or focus with the input of end-users, would prove to be a valuable research tool, and that IKT could help researchers think creatively about problems. All participants acknowledged challenges associated with this approach to research. We argue that biomedical scientists are open and eager to engaging in IKT but are held back by a lack of concrete examples and experiences to draw on. Integrating end-users and research scientists is an important step in ensuring end-users receive the research knowledge they require and that research is created to address their pressing needs.
\end{abstract}

Keywords Co-production of Knowledge, Collaborative Health Research, Qualitative, Knowledge Translation, Integrated Knowledge Translation

\section{Introduction}

There has been increasing recognition of the importance of end-users, such as the public and patients, to be involved with health policy, health care, and indeed even health research. Such collaborative models have been touted to have many benefits, but specifically end-user involvement in research can improve recruitment, quality, relevance and acceptability of research. [1-7] Integrated Knowledge Translation (IKT), as it is referred to in Canada, represents active collaboration between researchers and end-users throughout the entire research journey, not just at the end of the project as with other forms of Knowledge Translation (KT). In this, end-users are vital to the research, woven in at every stage, and sit as equal partners in the true co-production of knowledge. [8] It has been suggested that IKT represents a gold standard for addressing the gap between knowledge and end-user action [9] as the complex and interdisciplinary character of most health problems means that end-user involvement can increase the uptake of findings and encourage researchers to undertake relevant science. To increase the odds of knowledge implementation, IKT structures the research as a process of interaction and exchange among the producers and users of knowledge to ensure that the answers being sought will speak to end-user priorities [10]. Moreover, collaborative efforts can strengthen relationships between diverse communities (such as academics and end-users), potentially leading to organizational-level learning [11] and future pathways for knowledge sharing. [9]

By emphasizing non-linear knowledge creation and deemphasizing power hierarchies and disciplinary boundaries this process represents a challenge to the traditional biomedical paradigm. [12] This may help explain why IKT has tended to be exclusively practiced by only "researchers in some fields for some problems." [8] Application to clinical or large scale biomedical research has been rare [13] and when done, end-user involvement appears 
fragmented. [2] Indeed, Gagliardi and colleagues [13] found only 13 studies since 2004 that explicitly enacted an IKT model in their research, none of which were fundamentally biomedical or clinical in nature and many of which reported struggling with varying visions of roles for collaborators and goals for the project.[14-16]

While end-user collaboration may be considered the gold standard in research, the lack of empirical examples of IKT in biomedical studies is notable. We remain uncertain as to how we actually do IKT within a large-scale biomedical study.[8,17] How do we develop and sustain research-knowledge user partnerships and what are the roles, responsibilities and activities of partners? If other applications of IKT have found difficulty reconciling the goals and visions of their partners, what does this mean for research which asks two seemingly very different communities - biomedical scientists and knowledge end-users - to co-produce knowledge?

We attempt to tackle some of these gaps through a five-year experiment involving a pan-Canadian research initiative related to the causes and treatment of the epidemic of food allergy. At the onset, the clinical and basic research scientists involved in this project consented to not only be the researchers, but to be the researched. A similar investigation of the end-users is subject of a companion paper.[18] This study aims to explore baseline knowledge, attitude and practices of Canadian biomedical scientists towards IKT as a foundation for a funded program of research related to causes and treatments of an emerging public health epidemic. In other words, we ask: are Canadian scientists ready to take the plunge into a co-production of biomedical research?

\subsection{Context: the GET-FACTS Project}

GET-FACTS is a clinical research project funded by the Canadian Institutes of Health Research. The program of research is designed to investigate food allergy origins, causes and treatment. Approximately $7.5 \%$ of Canadians self-report at least one food allergy.[19] Not only can anaphylactic reactions can be fatal, living with food allergy has been documented to impact quality of life, with food allergic individuals constantly balancing physical safety and social wellbeing.[20-24] Given this context, there is pressing need for research on the origins, determinants and treatment of food allergy, and to have that knowledge effectively mobilized by end-users.

The GET-FACTS researchers represent nine universities across Canada and a multitude of disciplines. The project is built around four pillars of research: i) genetic determinants of food allergy and tolerance; ii) environmental impact on functional and immunological tolerance to foods; iii) novel biomarkers to assess allergy and tolerance; and iv) an end-user driven research agenda through IKT. While many research projects build in a plan for KT activities to occur passively at the end of a research program (known as 'end of grant' KT), GET-FACTS is committed to see KT be part of not just knowledge dissemination, but knowledge creation.

A key element to the GET-FACTS KT, as built into the proposal and since brought to action, is the establishment of an end-user steering committee used to identify issues and help prioritize the research agenda as well as identify the KT opportunities and potential outcomes associated with the project. Members of this committee include selected research scientists from the project and representatives from Canadian organizations that deal with patient advocacy and policy (municipal, provincial and federal) in the realm of food allergy. The steering committee meets in person twice annually, and remains in contact through teleconferences, monthly bulletins, scheduled webinars led by the scientists, and regular email exchanges. The vision of the GET-FACTS project is to have the steering committee meet regularly with scientists from all research projects under the GET-FACTS umbrella and freely exchange questions and ideas. With this, the steering committee could potentially serve as both a sounding board for researchers along the journey of GET-FACTS (the co-production of knowledge); as well (especially with a better understanding of the research undertaken) a ready quality source for knowledge dissemination. One of the salient questions going into this research was: how prepared and receptive are the research scientists for a new model of end-user engagement?

\section{Materials and Methods}

While this project is part of a larger research program designed to investigate IKT in biomedical research, this paper focuses on the objective of exploring previous experiences and perspectives of biomedical scientists on the integration of end-users into the research process. Qualitative semi structured in-depth interviews were therefore used in order to provide an opportunity to explore narratives and experiences of the participants, explore feelings based on these experiences and generate ideas for successful collaboration.

After receiving ethics approval from the University of Waterloo Office of Research Ethics (ORE \#: 19735), all research scientists associated with GET-FACTS $(\mathrm{N}=16)$ were invited to participate; $100 \%$ agreed. Participants were interviewed by phone between June and October 2014 (year one of the GET-FACTS project) by the first author. Interviews lasted between 29-54 minutes and were audio-recorded with permission. The interview questions were informed by the research objectives, probing i) participant background and previous experience working in collaborative research; ii) participant reflections on KT broadly; and, iii) participant familiarity and reflections on the GET-FACTS model of IKT. Theoretical saturation was met by the end of the interviews as no new data or concepts appeared.[26]

\subsection{Analysis}

Audio files were transcribed verbatim by a member of the 
research team and reviewed by the first author. After a thorough review of the literature, a thematic analysis ensued. A thematic analysis is the search for notable "themes" which are important for describing the phenomenon in question and involves reviewing data to explore both the research goals and any emergent issues. This method allows for pattern recognition within the data, which is carefully read and re-read throughout the process. Pattern recognition in our study occurred both deductively (based on the research objectives and interview guides) and inductively (themes emerging from the interview transcripts).[25]

The first author, who conducted all interviews, reviewed all transcripts and from this created an initial thematic set of codes to identify relevant data, broadly sorted into themes and sub-themes.[25] This initial set was then used independently by the first and second authors for a detailed review and pilot coding of three randomly selected transcripts. The authors then met to discuss their coding and noted any differences or missing codes. The code set was amended to these changes and using QSR International's NVivo for Mac 10.2 the theme code set was then used to code all the transcripts. To enhance consistency and reliability,[26] the first author led all steps of the coding and analysis process and the second author provided feedback and participated in interpretation of the findings. Coding was assessed for inter- and intra-rater reliability [27] achieving an $80 \%$ agreement with the alternative coder.

\section{Results}

The results below report on the two primary themes that emerged from the data: scientists' experiences and reactions date with $\mathrm{KT}$ as a concept and $\mathrm{KT}$ as a program in Canada, and reflections and reactions to being involved in an end-user research collaboration (IKT) going forward. The sub-themes are explored further in sections 3.1 and 3.2. A summary of key sub-themes can be found in Table 1 and Table 2.

\subsection{Experiencing Knowledge Translation}

All participants had heard the term "Knowledge Translation" and when asked what KT meant to them, the most frequent response (10 participants) reflected on the communication or dissemination of science:

[Science is] essentially like a different language, and you need to be able to translate that information back to the people who are going to use it. So we have to do this to make people understand why research is important and what these findings mean, and also what they don't mean, because I think that gets misconstrued a lot in the media. (Scientist \#16)

In contrast, nine participants made the connection between knowledge and action when describing KT:

Well what it means to me is that [the] facts and knowledge generated by scientific discovery can then be used in some sort of practical way for the people or patients who need it. (Scientist \#5)

Table 1. Experiencing Knowledge Translation (KT)

\begin{tabular}{|c|c|}
\hline Theme & Sub-theme \\
\hline \multirow{4}{*}{ Meaning of KT } & Communication/dissemination of science $(\mathrm{n}=10)$ \\
\hline & Connecting knowledge to action $(\mathrm{n}=9)$ \\
\hline & Trendy, buzz word $(\mathrm{n}=4)$ \\
\hline & Vague, confusing $(\mathrm{n}=4)$ \\
\hline \multirow{3}{*}{$\begin{array}{c}\text { Role of } \\
\text { scientists in KT }\end{array}$} & Communication through scientific literature $(n=4)$ \\
\hline & $\begin{array}{l}\text { Communication, interpretation and education at } \\
\text { the end of the project }(\mathrm{n}=8)\end{array}$ \\
\hline & $\begin{array}{c}\text { Interacting with end-users throughout the research } \\
\text { journey }(n=4)\end{array}$ \\
\hline
\end{tabular}

Table 2. Potential for integrated Knowledge Translation (IKT)

\begin{tabular}{|c|c|}
\hline Theme & Sub-theme \\
\hline \multirow{4}{*}{ IKT benefits } & $\begin{array}{l}\text { Improve dissemination of research findings } \\
\qquad(\mathrm{n}=16)\end{array}$ \\
\hline & Improved action from dissemination $(n=4)$ \\
\hline & $\begin{array}{l}\text { Research will better focus on issues relevant to } \\
\text { end-users }(n=10)\end{array}$ \\
\hline & Research can be shaped by end-user input $(\mathrm{n}=10)$ \\
\hline \multirow{3}{*}{ IKT challenges } & $\begin{array}{l}\text { End-users unable to put science into context } \\
\qquad(\mathrm{n}=7) .\end{array}$ \\
\hline & $\begin{array}{c}\text { End-user expectations regarding science must be } \\
\text { managed }(\mathrm{n}=4)\end{array}$ \\
\hline & $\begin{array}{l}\text { Dealing with group dynamics - multiple issues } \\
\qquad(\mathrm{n}=10)\end{array}$ \\
\hline \multirow{3}{*}{$\begin{array}{l}\text { Creating a } \\
\text { successful } \\
\text { collaboration }\end{array}$} & $\begin{array}{l}\text { Responsibility of scientists: remain positive in } \\
\text { their attitudes }(n=6) \text {; open minded in their } \\
\text { approaches }(n=5) \text {; listen more than talk }(n=5) \text {. }\end{array}$ \\
\hline & $\begin{array}{l}\text { Responsibility of end-users: communicate needs } \\
\text { to the scientists }(n=6) \text {; open minded to } \\
\text { collaboration }(n=6) ; \text { be motivated }(n=4)\end{array}$ \\
\hline & $\begin{array}{l}\text { Responsibility of project as a whole: planning } \\
\text { around communication gap }(\mathrm{n}=8) \text {; Planning } \\
\text { around power imbalances between scientists and } \\
\text { steering committee members }(\mathrm{n}=4)\end{array}$ \\
\hline
\end{tabular}

The most common type of 'action' suggested was a change in practice for physicians, or the creation of new policies based on research findings. Yet, many also saw KT as a burden - something to be 'complied with' in order to achieve certain goals (e.g., secure grants) $(\mathrm{n}=2)$ and some $(n=4)$ suggested it is simply a buzz word thrown around at grant writing time and generally too vague or confusing to be of any use:

Well it is basically, to me it is a buzz word... people keep using it, and you say it in grants, in publications and things like that... (Scientist \#8)

I have been to a [workshop] where someone from [the Canadian Institutes of Health Research] came for a half hour session and talked to us about 
knowledge translation. And honestly, after that half hour, I was like 'now I am twenty times more confused than before.' (Scientist \#13)

Reflecting on the personal role that scientists should play in KT, participant opinions varied widely but can essentially be grouped into three broad categories. First, $(n=4)$ were those that said the 'role' was exclusively to conduct the science and bring understanding to the mechanisms of health and disease. Participants in this category emphasized that KT was only a matter of communication through the scientific literature:

\section{I really think that fundamental research without translation is the key for science, and I am not sure that I agree with the way that [granting agencies] are pushing science towards translation. (Scientist \#8)}

Second, were the scientists $(\mathrm{n}=8)$ who saw an important role for KT, but one that primarily centred around communication, interpretation and education after the science is complete:

\begin{abstract}
[We have to] be able to communicate results and understand that even as basic scientists, you are not communicating just with fellow scientists. You have to communicate at all levels. (Scientist \#11)
\end{abstract}

The third and final category $(\mathrm{n}=4)$ indicated that they viewed the scientist's role in KT in a much broader sense. These participants argued that KT is and should be a fundamental aspect in all scientific research and that interacting with end-users throughout the research journey is a key part of a scientist's role:

So the people who are really doing the science need to become proactive about interfacing with the public and with users and with industry and with groups and say: 'this is an area we really should be going to and this is what we need to know from you to know if we are going in the right direction.' (Scientist \#2)

All 16 participants reflected on the challenges for biomedical scientists when engaging in KT activities. The most prominent challenges cited were time constraints $(n=6)$, financial restraints $(n=4)$, grant expectations $(n=4)$, academic culture or academic responsibilities $(n=4)$, a lack of training or experience $(n=3)$ and poor communication skills $(n=3)$. For example, one participant notes:

We've never received any formal training in that area. Certainly, when I trained that was a term that never really existed. There just had not been any formal training, so we tend to believe it's merely getting that information out there in the normal scientific channels, but clearly it's much more than that. (Scientist \#4).

\subsection{The GET-FACTS Model of IKT}

As named investigators on the GET-FACTS project, all participants had previously received a copy of the final research proposal (indeed, were central in its creation). The proposal clearly indicated that the KT component of GET-FACTS shared equal weight with the other scientific pillars of the GET-FACTS protocol. The proposal also laid out the agenda for the IKT partnerships. Yet, when the interviews were conducted approximately one year post-submission, only four of the participants could fully recall the KT component while seven participants reported knowing nothing of the KT component. The remainder of participants $(n=5)$ could roughly describe the KT design, but significant gaps in their knowledge emerged throughout the interviews.

After an update on the milestones from the first few months of the project, participants were asked to reflect on their immediate impressions of the model. All participants $(n=16)$ pointed to its positive aspects as well as potential challenges. First, all participants reported they could envision an improvement in the dissemination of research findings as a result of the IKT model adopted within GET-FACTS:

So it's having someone to act as an intermediate between the scientists, the results in journals and the patients. Someone to translate, as in put into lay language - I think that must improve the speed of that process. (Scientist \#6)

As well, some $(\mathrm{n}=4)$ pointed to not just dissemination but true action that would result from an IKT model in which end-users are empowered with the science:

When our stakeholders hear about this, if they pick up on a piece of information they need, they're the ones who are calling their [representatives in government], they're the ones who are showing up at the schools, and they're going to say 'I know someone who is doing research and this is what they found.' (Scientist \#3)

Most prominently, the biomedical scientists reported a sense that having an end-user driven steering committee for GET-FACTS could ensure the research will focus on topics relevant to end-users $(\mathrm{n}=10)$ :

[This model means] I am going to tell you what I am going to do before I do it, and ask for you to critique or add suggestions or potentially identify and critique my hypothesis prior to initiating my scientific engagement. So that is a very different kind of a model, because in a sense it is asking for the end-users to become scientists, and to become more involved in the scientific process. It could, in many ways, potentially improve that scientific process. (Scientist \#11)

While six participants said that the steering committee 
would not change their research direction or focus (which is actually counter to the GET-FACTS IKT protocol), the majority of participants $(n=10)$ said that the research could indeed be shaped by their input:

\section{If you believe the free exchange of ideas is the way to come up with outside the box thinking, then the steering committee is a potential place for that. So even though Joe Schmo doesn't know anything about [the science], but says, 'well it doesn't make sense that $X, Y, Z$ ' and I say, 'well you know the data is this, this and this' and he says, 'well yea but you know this, this and this' and he comes up with an idea. You take that little piece and you put it into the box, and you go, huh, that is an interesting way of looking at it. I had not considered that. That is where this free exchange of ideas could be potentially paradigm altering, because people do get stuck in their paradigms. (Scientist \#7).}

Many participants also felt that having the IKT element within GET-FACTS could prove to be a valuable tool in their research. For example, pragmatically, the steering committee could be a resource for patient recruitment or a resource for ethical quandaries that arise from the research process. For example, the GET-FACTS researchers studying the genetic causes of peanut allergy may uncover other health risks in their participants. The researchers are left to decide, "how do we get this genetic information back to people, and who wants to know how much?" Participants also suggested that the steering committee could act as a sounding board, representing the interests of the patients, and have input into the many decisions made as part of the research process.

Beyond the practical benefits, participants also spoke to the larger or long-term benefits that the GET-FACTS IKT model would engender. Some saw it as a way to acknowledge and legitimize the concerns of end-users and the public $(\mathrm{n}=5)$, and thereby increase trust between scientists and end-users. Others $(\mathrm{n}=2)$ pointed to this as a way to train a new generation of scientists, so that they would go forward with different ideas and attitudes about $\mathrm{KT}$; as well, that this was a way of testing out a new paradigm for biomedical research.

Participants also recognized that this IKT model would have its challenges. Chief among these, participants were concerned steering committee members without academic training might not be able to put the science into context $(n=7)$. For instance, three participants said there was a possibility that results would be translated too soon and without the necessary perspective:

The problem with this concept is this idea of the tweet, the immediate translation, and the danger translating something without appropriate and full understanding of what the scientists are saying. (Scientist \#7)
This concern was linked to the relatively slow pace of scientific advancement in comparison to the public's need for quick and immediate answers.

Well at the basic science level we do make real
advances if you look over a ten-year span [...] but
you don't necessarily see those year to year very
clearly. It depends on the nature of the project. So
if it is a clinical study and you are looking at
desensitization, it may be easier to see [advances]
than if you are looking at some regulatory T
cells... (Scientist \#9)

Similarly, some participants were concerned steering committee members would only be interested in cures, and not the mechanisms of the disease, in order to hasten the research process and produce tangible results $(n=3)$, and expressed the importance of managing steering committee members' expectations in regards to the pace of research $(n=4)$.

Participants also spoke about challenges in a broader sense $(n=10)$, not specific to this research. They asked, how can the needs of the steering committee members be met? How can we ward off attrition of steering committee members? How will GET-FACTS keep track of the messages being disseminated from different members of the steering committee? How can the project keep scientists active and involved given their time demands?

When asked directly, "what will it take to make this a successful collaboration?" respondents reported one of three types of answers. First, many responded that this responsibility lay with the scientists. It was said that scientists needed to: remain positive in their attitudes $(n=6)$ and open minded in their approaches $(n=5)$ towards the steering committee and the IKT model. It was suggested that, counter to traditional interactions between scientists and end-users, scientists should not talk at - or talk over the steering committee members $(n=5)$. That is to say, success will happen if "the scientists have big ears and small mouths" (Scientist \#5). This means that it will be very important for scientists to listen to end-users more than they speak to offer their own opinions. This is a highly significant result, as it runs against the norm of most interactions between scientists and end-users, where usually a scientist is invited to speak to their expertise. Second, some participants pointed to the responsibilities of the steering committee members. It was suggested that they should be motivated $(n=4)$ and open minded about their approach to the collaboration $(\mathrm{n}=6)$. They should also be vocal about their perspectives and needs and be able to communicate those to the scientists $(n=6)$. The theme of openness to new approaches is captured through Scientist \#2:

In order to do proper KT you have to have both parties open and willing to listen. So scientists have the humbleness to say 'we don't know everything but we are going to try hard to develop some concepts that are important.' And we have to 
have stakeholders that say 'we have an agenda, i.e. we want to improve children's health, but we're willing to listen to the message that $x$ isn't helpful but y could be helpful, even though we might [have] come in thinking otherwise.' (Scientist \#2)

Finally, participants spoke of aspects of the project as a whole that could help to ensure success. This included recognizing that there is a two-way communication gap between steering committee members and the scientists, and therefore planning around it $(n=8)$. Dealing with this gap could mean selectively choosing which scientists are best to speak to the steering committee $(n=3)$, prioritizing some messages about the research above others $(n=3)$, or providing a preamble to all science talks on the implications of translating too soon $(\mathrm{n}=1)$ :

Find out what they need, and what they want, because a lot of them come into this scientific environment and they get pretty tongue tied, and they don't know what to tell you. You need an unintimidating environment to get things going. (Scientist \#14).

Participants also said that the project should try to defy any natural power imbalances between scientists and steering committee members $(n=4)$. For this, the fostering of an "informal environment" would be important. As one participant notes, "Sit down in an informal fashion, and find out what they need. Otherwise it changes the whole code of what you are doing" (Scientist \#5).

\section{Discussion}

Evidence in and of itself is not enough to affect change. Addressing the knowledge to action gap has therefore become an increasing priority for researchers, policy and decision makers, funding agencies and end-users. Using Graham et al.'s KTA Framework[28,29] we can conceptualize this process as having two components: the creation of knowledge (including inquiry, synthesis and products or tools) and the sharing of knowledge (where selected evidence is tailored to specific context and end-user needs). In this context IKT is understood as the simultaneous conduct and application of both these components of the KTA Framework, where research is conducted with ongoing meaningful input from end-users, theoretically ensuring that the knowledge being created is useful to those in need of it. Yet while we know that the co-production of knowledge between end-users and scientists has many potential benefits [9] we have yet to flesh out the operational aspects of IKT in large-scale biomedical research.

The GET-FACTS project is forging new ground in biomedical research through an IKT approach that embraces end-users as co-producers of knowledge. In this, knowledge creation and practice are occurring simultaneously in such a way that forgoes conventional models of KT. Given the rarity of such an approach and knowing that previous IKT projects[14] faced difficulty aligning the visions and goals of their collaborators, we sought to understand the knowledge, attitudes and practices of IKT among the research scientists on GET-FACTS as it began through a qualitative exploratory methodology.

Investigators in the GET-FACTS project in many ways reflect a new breed of scientist. The large majority of these scientists not only had worked previously as part of a large interdisciplinary team, but also had interacted with end-users as they conducted their research. However, none of the scientists had participated in research that included end-users to the degree of the GET-FACTS model; that is, in the actual creation of knowledge - this was a new experience. While the scientists on this research project told us they had been exposed to the term "Knowledge Translation" $[28,29]$ yet there was a wide range of interpretations as to its meaning. Indeed, the majority interpreted KT something that occurred after knowledge has been created, often referred to as end of grant KT. This finding echoes earlier work, which found that communication from scientists to the public was dominated by a framework of one-way transfer of information; the scientist's job was to create knowledge and 'educate' the public.[30]

Given that end of grant KT has dominated the KT landscape to date, our finding is not out of context. However, with increasing recognition of the benefits of an IKT approach and with exposure to the IKT model within the original GET-FACTS proposal, it is surprising that only a quarter of our participants considered KT to include a 'back and forth' between researchers and end-users. We suggest that this result is likely an artefact of both exposure and time. While participants in this study were exposed to end-users in other aspects of their work and were willing to engage in KT, they had not yet had a chance to see an IKT project up close. Remembering that IKT has to date only been practiced by "researchers in some fields for some problems," [8] this is a new experience biomedical scientists.

The results of this study show that there is tremendous potential for IKT in large-scale biomedical research. Though participants had focused on end of grant aspects when broadly describing KT, there was substantial engagement and interest when the GET-FACTS IKT model was discussed in the interviews. Even those participants who had limited experience interacting with end-users could point to the potential benefits of having end-users working with the research scientists throughout the knowledge creation process. Participants viewed the benefits of IKT from a pragmatic perspective - it could benefit dissemination, patient recruitment or be a resource for tackling ethical quandaries that arise over the course of the project. Perhaps more importantly, participants also said that steering committee input could change the research focus and challenge research scientists to think about new 
problems, or old problems in new ways, and tackle them from new directions. End-users could become a fundamental part of the science and this could potentially improve the scientific process. As one participant phrased it, this could be "potentially paradigm altering."

Others have documented some of the organizational and cultural demands that keep scientists from fully engaging with KT activities.[31] Given the greater time and effort required for IKT compared to traditional $\mathrm{KT}$ models, the recognition by participants of the benefits of the GET-FACTS IKT model is promising. Having said that, there was also acknowledgement of the challenges the project may face in recognition of the divide between scientists and the steering committee in both perspectives and goals. This challenge has been acknowledged by other projects that have embraced the IKT model[14] and harkens back to the "two-communities" theory, which suggests that scientists and end-users come from distinct worlds[32,33] that cannot and will not be integrated. However, in theory, the IKT approach should provide the bridge between these worlds.[9] Hearing the concerns of scientists in this project, GET-FACTS has adapted to include greater touch points between collaborators and therefore greater opportunity to align the goals and visions of its participants. Only time (and experience) will tell us if the IKT model can help us bridge these worlds.

\section{Conclusions}

As research into the origins and treatment of food allergies is ongoing, individuals and families of those with food allergies struggle to find information to help them balance the physical and social impacts of this condition. The challenge of translating research knowledge into useable and actionable information is a dominating concern for researchers, policy makers and end-users alike. IKT, the active collaboration between researchers and end-users throughout the entire research journey, has been suggested as a viable mechanism for strengthening communication and producing research speaks to end-user needs.

With the rare application of IKT to biomedical research, this work highlights the gap between theory and empirical use, and therefore the need to continue pursuing this IKT framework. We argue that biomedical scientists are open and eager to engaging in IKT but are held back by a lack of concrete examples and experiences to draw on. Integrating end-users and research scientists is an important step in ensuring end-users receive the research knowledge they require and that research is created to address their pressing needs. These findings are of interest for any group or research project seeking to make research more meaningful through the integration of end-users throughout the research process. Our larger project evaluating the implementation of IKT within GET-FACTS continues, with data being collected from both scientists and steering committee members. We aim to ultimately produce and distribute a protocol document to serve as future reference for other research projects. With time and experience produced from the GET-FACTS project there is great potential to change the way that biomedical research in Canada and internationally is conducted - and to assist biomedical research scientists to take the plunge into end-user collaborative research agendas.

\section{Acknowledgements}

The authors would like to acknowledge the GET-FACTS scientists for their time and participation, the GET-FACTS steering committee for their input through the process and the Canadian Institutes of Health Research (CIHR) who provided funding for the GET-FACTS project. 


\section{Appendix:}

\begin{tabular}{|c|c|}
\hline \multicolumn{2}{|c|}{ Qualitative interview flexible checklist } \\
\hline Question & Probe \\
\hline $\begin{array}{l}\text { Could you start by telling me briefly about how did you become involved in the } \\
\text { GET-FACTS team? }\end{array}$ & What specifically is your research focus? \\
\hline Have you worked with large interdisciplinary teams before? & Tell me about that... \\
\hline \multicolumn{2}{|l|}{ When I say the term "Knowledge Translation" what does that mean to you? } \\
\hline $\begin{array}{l}\text { CIHR has said that Knowledge Translation is a fundamental part of their mandate. } \\
\text { What role do you see basic and clinical scientists having in Knowledge Translation? }\end{array}$ & Are there any practical restraints on this? e.g. workload... \\
\hline \multicolumn{2}{|l|}{$\begin{array}{l}\text { Do you have previous experiences working with stakeholders/non-scientists in the } \\
\text { research process? }\end{array}$} \\
\hline If yes, how did you find that experience? & Can you tell me a bit about it? \\
\hline \multicolumn{2}{|l|}{$\begin{array}{l}\text { What do you know (or remember) of the Knowledge Translation model that } \\
\text { GET-FACTS is utilizing?) }\end{array}$} \\
\hline $\begin{array}{l}\text { Overall /generally, what are your impressions of the GET-FACTS Knowledge } \\
\text { Translation model? }\end{array}$ & $\begin{array}{l}\text { What do you think will be 'successful' or positive in } \\
\text { trying to do research in this way? Explain... } \\
\text { What do you think will be challenging in trying to do } \\
\text { research in this way? Explain. }\end{array}$ \\
\hline $\begin{array}{l}\text { Do you anticipate that the feedback from stakeholders will change or shape your } \\
\text { research? }\end{array}$ & Why/why not? In what ways? \\
\hline $\begin{array}{l}\text { Do you anticipate this Knowledge Translation model could chance the speed or } \\
\text { impact of your research? }\end{array}$ & Why/why not? In what ways? \\
\hline $\begin{array}{l}\text { Do you think the end-user driven model of research might change the efficiency of } \\
\text { research? }\end{array}$ & How do you feel about this? \\
\hline $\begin{array}{l}\text { We have not yet had any scientist-stakeholder joint meetings. What do you think } \\
\text { would make this a successful collaboration? }\end{array}$ & $\begin{array}{l}\text { For instance, can you name attributes of the steering } \\
\text { committee that would be important for the success of } \\
\text { GET-FACTS? } \\
\text { Can you think of attributes from the scientists that would } \\
\text { equally be important? }\end{array}$ \\
\hline $\begin{array}{l}\text { Is there anything else that you would like to add? } \\
\text { Do you have any questions for me? }\end{array}$ & \\
\hline
\end{tabular}

\section{REFERENCES}

[1] K. Froggatt , C. Goodman, H. Morbey, S.L. Davies, H. Masey, A. Dickinson, W. Martin, C. Victor. Public involvement in research within care homes: benefits and challenges in the APPROACH study, Health Expect, Vol. 19, 1336-1345, 2016

[2] N.D. Shippee, J.P. Domecq Garces, G.J. Prutsky Lopez, et al. Patient and service user engagement in research: A systematic review and synthesized framework, Health Expectations, Vol.18, No.5, 1151-1166, 2015.

[3] P. Moule, R. Davies. A devolved model for public involvement in the field of mental health research: case study learning, Health Expect, Vol.19, 1302-1311, 2016.

[4] K. Golden-Biddle, T. Reay, S. Petz, et al. Toward a communicative perspective of collaborating in research: The case of the researcher-decision-maker partnership, J Health Serv Res Policy,Vol.8, Suppl.2, 20-25, 2003.

[5] V.A. Entwistle, M.J. Renfrew, S. Yearley, J. Forrester, T. Lamont. Lay perspectives: Advantages for health research, BMJ, Vol.316, No.7129, 463-466, 1998.

[6] S. Ross, J. Lavis, C. Rodriguez, J. Woodside, J.L. Denis. Partnership experiences: Involving decision-makers in the research process, J Health Serv Res Policy, Vol.8, Suppl. 2, 26-34, 2003.

[7] A. Kitson, K. Powell, E. Hoon, J. Newbury, A. Wilson, J. Beilby. Knowledge translation within a population health study: How do you do it, Implementation Science, Vol.8, No.54, 2013.

[8] S. Bowen, I.D. Graham. Integrated knowledge translation. In: S. Straus, J. Tetroe, Graham ID, eds. (pp.14-21). Knowledge translation in health care: Moving from evidence to practice, John Wiley \& Sons, 2013.

[9] A. Kothari, C.N. Wathen. A critical second look at integrated knowledge translation, Health Policy, Vol.109, No.2, 187-191, 2013.

[10] N. Jacobson, D. Butterill, P. Goering. Development of a framework for knowledge translation: Understanding user context, J Health Serv Res Policy, Vol.8, No.2, 94-99, 2003.

[11] I. Walter, H. Davies, S. Nutley. Increasing research impact through partnerships: Evidence from outside health care, J Health Serv Res Policy, Vol. 8, 58-61, 2003.

[12] V. Lapaige. "Integrated knowledge translation" for globally oriented public health practitioners and scientists: Framing together a sustainable transfrontier knowledge translation vision, Journal of Multidisciplinary Healthcare, Vol.3, 33-47, 2010.

[13] A.R. Gagliardi, W. Berta, A. Kothari, J. Boyko, R. Urquhart. 
Integrated knowledge translation (IKT) in health care: A scoping review, Implementation Science, Vol.11, No.38, 2016.

[14] A. Kothari, S.L. Sibbald, C.N. Wathen. Evaluation of partnerships in a transnational family violence prevention network using an integrated knowledge translation and exchange model: A mixed methods study, Health Research Policy and Systems, Vol.12, No.25, 2014.

[15] P.J. McGrath, P. Lingley-Pottie, D.J. Emberly, et al. Integrated knowledge translation in mental health: Family help as an example, Journal of the Canadian Academy of Child and Adolescent Psychiatry, Vol.18, No.1, 30-37, 2009.

[16] M. Preyde, J. Carter, R. Penney, K. Lazure, J. Vanderkooy, P. Chevalier. Integrated knowledge translation: Illustrated with outcome research in mental health, Journal of Evidence-informed Social Work, Vol.12, No.2, 175-183, 2015.

[17] J.M. Tetroe, I.D. Graham, R. Foy, et al. Health research funding agencies' support and promotion of knowledge translation: An international study, Milbank Q., Vol. 86, No.1, $125-155,2008$.

[18] J. Dixon, S.J. Elliott, A.E. Clarke. Exploring knowledge-user experiences in integrated knowledge translation: a biomedical investigation of the causes and consequences of food allergy. Research Involvement and Engagement, Vol.2, No.1, 27, 2016.

[19] J. Fereday, E. Muir-Cochrane. Demonstrating rigor using thematic analysis: a hybrid approach of inductive and deductive coding and theme development. Int J Qual Methods, Vol.5, No.1, 1-11, 2006.

[20] N.E. Fenton, S.J. Elliott, L. Cicutto, et al. Illustrating risk: anaphylaxis through the eyes of the food-allergic child, Risk Analysis, Vol.31, No.1, 171-183, 2011.

[21] L. Soller, M. Ben-Shoshan, D.W. Harrington, et al. Prevalence and predictors of food allergy in Canada: A focus on vulnerable populations, The Journal of Allergy and Clinical Immunology: In Practice, Vol.3, No.1, 42-49, 2015.

[22] J. Dean, N.E. Fenton, S. Shannon, S.J. Elliott, A. Clarke.
Disclosing food allergy status in schools: Health-related stigma among school children in Ontario, Health \& Social Care in the Community, 10.1111/hsc.12244, 2015.

[23] S.K. Lu, S.J. Elliott, A.E. Clarke. Exploring perceptions and experiences of food allergy among new Canadians from Asia, J Allergy (Cairo), 2014.

[24] G. Du Toit, G. Roberts, P.H. Sayre, et al. Identifying infants at high risk of peanut allergy: The learning early about peanut allergy (LEAP) screening study, J Allergy Clin Immunol, Vol.131, No.1, 135-143, 2013.

[25] B.F. Crabtree, W.L. Miller. Doing qualitative research 2nd Edition ed. Sage Publications, USA, 1999.

[26] J. Baxter, J. Eyles. Evaluating qualitative research in social geography: Establishing 'rigour' in interview analysis, Transactions of the Institute of British Geographers, Vol.22, No.4, 505-525, 1997.

[27] H.B. Miles, A.M. Huberman. Qualitative data analysis: An expanded sourcebook, Sage, 1994.

[28] I.D. Graham, J. Logan, M.B. Harrison, et al. Lost in knowledge translation: Time for a map?, J Contin Educ Health Prof., Vol.26, No.1, 13-24, 2006.

[29] I.D. Graham, J.M. Tetroe. Getting evidence into policy and practice: Perspective of a health research funder, Journal of the Canadian Academy of Child and Adolescent Psychiatry, Vol.18, No.1, 46-50, 2009.

[30] S. Davies. Constructing communication. Science Communication, Vol.29, No.4, 413-434, 2008

[31] N. Jacobson, D. Butterill, P. Goering. Organizational factors that influence university-based researchers' engagement in knowledge transfer activities, Science Communication, Vol.25, No.3, 246-259, 2004.

[32] S. Bowen, P. Martens, The Need to Know Team. Demystifying knowledge translation: Learning from the community, J Health Serv Res Policy, Vol.10, No.4, 203-211, 2005 .

[33] N. Caplan. The two-communities theory and knowledge utilization, Am Behav Sci, Vol.22, No.3, 459, 1979. 